NBER WORKING PAPER SERIES

SOME THEORETICAL CONNECTIONS AMONG WEALTH, INCOME, SUSTAINABILITY, AND ACCOUNTING

\author{
Martin L. Weitzman \\ Working Paper 22060 \\ http://www.nber.org/papers/w22060 \\ NATIONAL BUREAU OF ECONOMIC RESEARCH \\ 1050 Massachusetts Avenue \\ Cambridge, MA 02138 \\ March 2016
}

The views expressed herein are those of the author and do not necessarily reflect the views of the National Bureau of Economic Research.

NBER working papers are circulated for discussion and comment purposes. They have not been peer-reviewed or been subject to the review by the NBER Board of Directors that accompanies official NBER publications.

(C) 2016 by Martin L. Weitzman. All rights reserved. Short sections of text, not to exceed two paragraphs, may be quoted without explicit permission provided that full credit, including ( $)$ notice, is given to the source. 
Some Theoretical Connections Among Wealth, Income, Sustainability, and Accounting Martin L. Weitzman

NBER Working Paper No. 22060

March 2016

JEL No. Q01,Q2,Q5

\section{ABSTRACT}

In theory, and under some quite strong assumptions, there exists an important rigorous quantitative relationship among the following four fundamental economic concepts: (1) "wealth"; (2) "income"; (3) "sustainability"; (4) "accounting". These four basic concepts are placed in quotation marks here because a necessary first step will be to carefully and rigorously define what exactly is meant by each concept. In this paper, I review what is known about this important fourfold quantitative relationship in an ultra-simplified setting. I identify some basic applications of this simplified economic theory of wealth and income (and sustainability and accounting). While the contents of this paper are expressed at a very high level of abstraction and require some restrictive assumptions, I believe that the fundamental four-fold relationship it sharply highlights is useful for understanding, at least in principle, what is "wealth" and what is its theoretical relationship to "income," "sustainability," and "accounting."

Martin L. Weitzman

Department of Economics

Harvard University

Littauer 313

Cambridge, MA 02138

and NBER

mweitzman@harvard.edu 


\title{
Some Theoretical Connections Among Wealth, Income, Sustainability, and Accounting
}

\author{
Martin L. Weitzman* \\ February 26, 2016 \\ for chapter of Wealth: Economics and Policy \\ preliminary and confidential \\ comments appreciated
}

\begin{abstract}
In theory, and under some quite strong assumptions, there exists an important rigorous quantitative relationship among the following four fundamental economic concepts: (1) "wealth"; (2) "income"; (3) "sustainability"; (4) "accounting". These four basic concepts are placed in quotation marks here because a necessary first step will be to carefully and rigorously define what exactly is meant by each concept. In this paper, I review what is known about this important four-fold quantitative relationship in an ultra-simplified setting. I identify some basic applications of this simplified economic theory of wealth and income (and sustainability and accounting). While the contents of this paper are expressed at a very high level of abstraction and require some restrictive assumptions, I believe that the fundamental four-fold relationship it sharply highlights is useful for understanding, at least in principle, what is "wealth" and what is its theoretical relationship to "income," "sustainability," and "accounting."
\end{abstract}

\section{Introduction: Some Heroic Assumptions}

Our task here is very ambitious, being nothing less than rigorously elucidating a strong quantitative theoretical relationship among the four fundamental economic concepts of: (1)

${ }^{*}$ Department of Economics, Harvard University (mweitzman@harvard.edu). As will become clear, this paper is in the nature of an essay that attempts to enlarge upon, clarify, and unify my own approach to what might be called "the pure theory of perfectly complete national income accounting." I do not attempt to do a proper survey or evaluation of the many other views on this vast subject. 
"wealth"; (2) "income"; (3) "sustainability"; (4) "accounting". In the course of dealing with these four fundamental economic concepts, we will be forced to deal also with such background concepts as "consumption", "investment", "investment prices", "capital", "the rate of return" (on investment, in units of consumption), and so forth. We will not get very far in the analysis without making several heroic assumptions that greatly simplify the problem under consideration via a particular "toy model." I believe that the heroic simplifying assumptions behind this toy model may be acceptable at a high level of abstraction because they will allow us to obtain sharp neat results, which can then serve as a conceptual point of departure for further analysis and applications. ${ }^{1}$

First of all, for utmost simplicity, I assume in this toy model that there is just one consumption good. (More generally the single consumption good could be interpreted as the "gain" or "payoff" of the system.) The assumption of a single consumption good allows for an unambiguous measure of "the" rate of return along a consumption-efficient trajectory, which, when this rate of return is additionally assumed to be constant over time, will play an important role in what follows. The rate of return in any period (along an efficient trajectory) is the extra consumption that could be obtained next period from curtailing consumption in this period by one unit, but otherwise leaving the rest of the efficient trajectory as is. ${ }^{2}$ The strong assumption of a single composite consumption good is stark, but it might be approximately appropriate for an ideal index number of aggregate consumption. In any event, I need this assumption, along with the further assumption of a constant rate of return, to get very sharp results. Effectively I am assuming the situation is "as if" the utility function is linear in consumption and the welfare criterion is "as if" it is present discounted consumption at the given constant rate of return. The more complicated general case of multiple consumption goods and a nonlinear utility function is treated in Weitzman (2003, Chapter 6, "The Pure Theory of Perfectly Complete National Income Accounting"), which the interested reader might consult. ${ }^{3}$ Here I am aiming at expositional simplicity. Let

\footnotetext{
${ }^{1}$ By now there exists a large literature on the four basic concepts of this paper and related subjects. (See, for example, as just a small subset, the extensive bibliography cited in Hamilton and Hartwick (2014).) Compared to this large literature, my own tendency (beginning with Weitzman (1970)) has been to sacrifice some generality in favor of a tight fully-rigorous quantitative formulation. There is a trade-off here between generality and elegance. Even the most frugal formulations in this field make very demanding assumptions on the economic framework and the completeness of prices and quantities. My attitude here is: "Why not go a little further with the basic assumptions to achieve full elegance?". In this paper I do not have space to do a proper literature survey of the numerous other approaches. Instead, I attempt to enlarge upon, clarify, and unify my own approach. The antecedents of this paper having roots in my own previous work (in addition to Weitzman (1970)) include Weitzman (1976) and Weitzman (2003). I consider the presentation here to be more sharply focused and more elegantly expressed than these previous expositions.

${ }^{2}$ For background on defining the rate of return for a single consumption good, see Solow (1963), who takes a similar approach to this paper.

${ }^{3}$ The general result in Weitzman (2003) has the spirit or flavor of the result in this paper, but is more
} 
consumption at time $t$ be denoted $C(t) .{ }^{4} \quad$ (In this paper the basic economic unit is the nation, but the same theory goes through for other settings, in which case $C(t)$ typically represents gain or payoff at time $t$.)

Unlike consumption, capital is intended from the beginning to be multi-dimensional, micro-specific, and all-encompassing. Indeed, the major purpose of this approach is to present the simplest case where there is a powerful connection among wealth, income, accounting, and sustainability for multiple investments in multiple capital goods. Consumption is already aggregated into one composite good, which serves as the numeraire, but capital is disaggregated into its many specific forms or types.

The notion of "capital" used here is quite a bit more general than the traditional produced means of production, like equipment and structures. Subsoil minerals are forms of capital. Fish stocks are forms of capital. More generally, natural resources of all types (renewable and non-renewable) are here considered to be forms of capital. Forms of human capital, such as education, skills, capabilities, and know-how should in principle be included, and also the knowledge capital accumulated from R\&D-like activities. In principle, social and institutional and intellectual-property capital should be accounted for (if only we knew how to quantify and price such concepts). Generally speaking, every possible type of capital ought to be included - to the extent that we know how to measure and evaluate at efficiency prices the associated flow of net investments. In principle, environmental assets should be treated as forms of capital. From this perspective, environmental quality might be viewed as a stock of capital that is depreciated by pollution and invested in by abatement. The underlying ideal is to have the list of capital goods be as comprehensive as possible, subject to the practical limitation that meaningful competitive-market-like efficiency prices are available for evaluating the corresponding net investments.

Suppose that altogether there are $n$ capital goods, including stocks of natural resources and other unorthodox forms. The stock of capital of type $j(1 \leq j \leq n)$ in existence at time $t$ is denoted $K_{j}(t)$ and its corresponding net investment flow is $I_{j}(t)=\dot{K}_{j}(t)$, where $\dot{K}_{j}(t) \equiv d K_{j}(t) / d t$. The $n$-vector $\mathbf{K}=\left\{K_{j}\right\}$ denotes all capital stocks, while $\mathbf{I}=\left\{I_{j}\right\}$ stands for the corresponding $n$-vector of net investments. In vector notation, $\mathbf{I}(t)=\dot{\mathbf{K}}(t)$, where $\dot{\mathbf{K}}(t) \equiv d \mathbf{K}(t) / d t$. Note that the net investment flow of a natural capital asset like a school of fish, a timber reserve, an oil field, or a pool of water would be negative whenever the

complicated, involving willingness-to-pay consumer-surplus-like measurements that effectively reconstruct the curved utility function. It is precisely to simplify this extra complexity that I treat here the special case of a single consumption good with a linear utility function, so that the relevant welfare criterion is present discounted consumption discounted at the given rate of return.

4 "Consumption" here should be broadly construed to include, e.g., public goods, externalities, the enjoyment of environmental amenities, and so forth, as well as conventional private consumption of goods and services. 
underlying asset is being depleted or run down more rapidly than it is being replaced or built up.

In a spirit of focusing sharply for the sake of developing the core theory, we assume that the "attainable possibilities" of the underlying production system are time autonomous. This means that the $(n+1)$-dimensional vector $(C(t), \mathbf{I}(t))$ is producible at time $t$ if and only if

$$
(C(t), \mathbf{I}(t)) \varepsilon A(\mathbf{K}(t))
$$

where $A(\mathbf{K})$ is the time-free $(n+1)$-dimensional attainable possibilities set as a function of capital stock $\mathbf{K}$. It is assumed that the attainable possibilities set $A(\mathbf{K})$ is convex, which will guarantee that necessary and sufficient conditions coincide in the optimal growth problem to be presented. ${ }^{5}$

\section{The Basic Optimal Control Problem}

As was already mentioned, the rate of return in any period along a consumption-efficient trajectory is the extra consumption that could be obtained next period from curtailing consumption in this period by one unit, but otherwise leaving the rest of the efficient trajectory as is. We now make yet-another heroic assumption that the economy is moving along an efficient trajectory where at all times the own rate of interest (or rate of return) on the single consumption good is the constant $r$. This might be considered a tolerable approximation for a great many practical purposes because it accords with a well-known "stylized fact" that the real rate of return has been essentially trendless over time, at least throughout the measurable past. ${ }^{6}$ One could try to argue that the economic entity corresponding most closely to this concept is the annual after-tax real return to capital (because it approximately defines the relevant intertemporal consumption trade-off faced by the average citizen in deciding how much to save). As a very rough approximation, a trendless round figure of $r \approx 4-5 \%$ per year might then be used for this real interest rate in the postwar period or even, perhaps, over longer historical periods. ${ }^{7}$

Some reflection reveals that such an economy moving along an efficient trajectory with

\footnotetext{
${ }^{5}$ This is not quite true. Technically speaking, I need more convexity in the sense that $(C(t), \mathbf{I}(\mathbf{t}), \mathbf{K}(\mathbf{t})) \varepsilon B$, where $B$ is a time-independent $(2 n+1)$-dimensional convex set of feasible alternatives. See Weitzman (2003) for further details. I implicitly assume that this stronger convexity condition is being met.

${ }^{6}$ Nordhaus (1994) in his section entitled "Empirical Evidence on the Return on Capital" summarizes a large number of studies that are consistent with a trendless interpretation. Indeed, this is one of Kaldor's famous "stylized facts" about the growth of advanced industrial economies. (For a discussion, see Solow (1970), p. 3.)

${ }^{7}$ Nordhaus (1995), Jorgenson (1994), or Feldstein (1997) could each be cited to justify trendless fluctuations in the rate of return averaging around $4-5 \%$ per year.
} 
own rate of interest on consumption equal to the constant $r$ must be a solution of the optimal control problem that maximizes the present discounted value of consumption at constant discount rate $r$. More formally, such a trajectory will

maximize

$$
\int_{0}^{\infty} e^{-r t} C(t) d t
$$

subject to the feasibility constraints (1) and the capital accumulation equation

$$
\dot{\mathbf{K}}(t)=\mathbf{I}(t),
$$

and with the given initial condition

$$
\mathbf{K}(0)=\mathbf{\Gamma}
$$

where $\Gamma$ stands for the initially given vector of capital stocks.

Because the maximand (2) is a weighted linear average of $\{C(t)\}$ with time weights $\left\{e^{-r t}\right\}$, the rate of transformation along the optimal trajectory between consumption at time $\tau$ and consumption at time $\tau^{\prime}$ is guaranteed to be $\exp \left(-r\left(\tau^{\prime}-\tau\right)\right)$. Thus, the solution of maximizing (2) (subject to constraints (1), (3), (4)) has the property of being an efficient consumption trajectory all along which the rate of return is the constant $r$. Conversely, an efficient consumption trajectory all along which the rate of return is $r$ must maximize (2) subject to constraints (1), (3), (4).

I note in passing that maximizing (2) (subject to constraints $(1),(3),(4)$ ) can be interpreted as an as-if optimal control problem. The underlying problem might be maximizing some complicated form of dynamic utility, but the solution is as if there is an efficient consumption trajectory all along which the rate of return is the constant $r$. This way of looking at things seems to me to be a more intuitive characterization than in terms of dynamic utility maximization. There might be some form of complicated dynamic utility maximization in the background, but the reduced form of a solution is as if it results in an efficient consumption trajectory along which the rate of return is the constant $r$. This as if form accords with the well-known "stylized fact" that the real rate of interest has been essentially trendless over time, at least throughout the measurable past. ${ }^{8}$ I am effectively assuming that we are in a special case where instantaneous "utility" is as-if identified with the single measurable consumption good whose rate of return is $r$.

An application of the famous maximum principle of optimal control theory to the "as if" problem here takes the following form. Introduce the $n$-dimensional investment-price row

\footnotetext{
${ }^{8}$ See the last two footnotes for a further exposition of this point.
} 
vector $\mathbf{P}=\left\{P_{j}\right\}$. Henceforth we adhere to the convention that all prices are row vectors and all quantities are column vectors. The current-value Hamiltonian expression $C+\mathbf{P I}$ is in the form of net domestic product (NDP) with consumption as numeraire. A function of $\mathbf{K}$ and $\mathbf{P}$ that will play a critical role in the maximum principle is the current-value maximized Hamiltonian expression

$$
\widetilde{H}(\mathbf{K}, \mathbf{P}) \equiv \max _{(C, \mathbf{I}) \varepsilon A(\mathbf{K})}\{C+\mathbf{P I}\}
$$

A feasible trajectory satisfies (1), (3), (4). With underlying convexity, the necessary and sufficient condition for a feasible trajectory $\left\{C^{*}(t), \mathbf{I}^{*}(t), \mathbf{K}^{*}(t)\right\}$ to be optimal is the existence of an investment-price trajectory $\left\{\mathbf{P}^{*}(t)\right\}$ satisfying for all $t$ the condition ${ }^{9}$

$$
\widetilde{H}\left(\mathbf{K}^{*}(t), \mathbf{P}^{*}(t)\right)=C^{*}(t)+\mathbf{P}^{*}(t) \mathbf{I}^{*}(t)
$$

and simultaneously satisfying everywhere along the optimal trajectory the vector differential equation

$$
\dot{\mathbf{P}}^{*}(t)=-\left[\frac{\partial \widetilde{H}}{\partial \mathbf{K}}\right]_{* t}+r \mathbf{P}^{*}(t),
$$

where $\dot{\mathbf{P}}^{*}(t) \equiv d \mathbf{P}^{*}(t) / d t$ and the subscript $* t$ denotes evaluation along an optimal trajectory at time $t$.

The maximum principle corresponding to the optimal control problem of this section represents an important dual-side interpretable as a dynamic competitive equilibrium. This dual interpretation allows us to gain insight into the nature of fully-accounted-for comprehensive NDP and its relation to income, wealth, and sustainability.

\section{Economic Interpretation of the Maximum Principle}

What is the economic interpretation of conditions (6) and (7)? Briefly, (6) and (7) are describing an economy-wide dynamic competitive equilibrium with a perfect capital market whose rate of return is $r$. There is a deep connection between maximization of (2) over time and competitive market equilibrium over time in an economy whose rate of return is $r$. Essentially, the basic invisible-hand theorem here says that an economic situation maximizing present discounted consumption (at discount rate $r$ ) is being optimally controlled over time if and only if the situation can simultaneously be interpreted as describing a dynamic perfectforesight competitive equilibrium with a perfect capital market paying rate of return $r$. If (2)

\footnotetext{
${ }^{9}$ See Weitzman (2003), as applied to the formulation of this paper. For convenience, here I am omitting the transversality condition at infinity. Again, see Weitzman (2003) for a full treatment of this aspect.
} 
is being maximized subject to constraints (1), (3), (4), then optimal investment levels must be accompanied by investment or capital prices (relative to a consumption numeraire price of 1) in such a way that any observers would swear they are witnessing the evolution of an economy with a perfect capital market in a dynamic perfect-foresight competitive equilibrium having rate of return $r$. Conversely, if price and quantity trajectories are behaving as if the model were describing a dynamic perfect-foresight competitive equilibrium with a perfect capital market having rate of return $r$, then it must constitute a solution to the problem of maximizing (2) subject to constraints (1), (3), (4).

A convenient thought experiment for conceptualizing a nation having a perfect capital market paying a real interest rate of $r$ is to postulate an imaginary national bank where any amount of consumption may be borrowed or deposited at real interest rate $r$, under the condition that all loans must eventually be paid off. The unit of account in this nation is the consumption good $C$, whose numeraire price is 1 . In effect, the national bank is a place where extra consumption can be deposited or borrowed at real interest rate $r$.

The perfectly competitive price of investment (or capital) good $j$ at time $t$ is $P_{j}^{*}(t)$. This means that at time $t$ any representative agent can buy or sell any amount of capital $K_{j}(t)$ (or net investment $I_{j}(t)$ ) at the given competitive price $P_{j}^{*}(t)$.

The first condition of the maximum principle (6) signifies that at all times representative agents are acting to maximize NDP, taking prices as given. Envisioning the optimal control problem here as a movie unfolding over time, condition (6) represents a "still frame" photographed at instant $t$. It is a static description, indicating that at time $t$ the economy is on its attainable possibilities frontier at a point where the marginal rates of transformation among current consumption and current investments, or among various forms of current investment, is exactly the current competitive prices of investments $\mathbf{P}^{*}(t)$.

Behind the scenes, the representative agents of the economy might be manipulating thousands, or even millions of intermediate control variables to attain by the "invisible hand" the maximized reduced-form value of NDP expression (6). The reduced form of even the most complicated static competitive equilibrium is that all intermediate control variables have been set (by internal competition in intermediate goods) so that the economy is placed on its attainable possibilities frontier at the precise point where marginal rates of transformation among final outputs (the one consumption good and the $n$ investment goods) are equal to their price ratios, which is exactly the reduced-form condition (6).

Condition (6) means that no matter how complicated are the internal workings of the competitive economy, any observers of these microeconomic inner workings will come away thinking that they are witnessing a static competitive equilibrium. As long as we maximize the Hamiltonian expression (6) over all control variables, including intermediate goods and 
services, it does not matter whether $\mathbf{I}$ is directly controlled, as in the compact formulation here, or whether it is indirectly controlled by an arbitrarily large collection of intermediate control variables. In the most abstract formulation, any number of control variables, subject to any number of intermediate-materials-balancing constraints in the background may be simultaneously determining consumption $C$ and net investment $\mathbf{I}$. The intermediate control variables are like dummy variables here - we are no more interested in them per se than we are interested in the details of intermediate goods like metallic ores or chemical feedstocks. We are ultimately interested only in the netted-out reduced-form attainable possibilities set $A(\mathbf{K})$ setting out feasible combinations among $C$ and $\mathbf{I}$ as a function of $\mathbf{K}$. None of the background detail about control variables representing intermediate goods or about intermediate control sets really matters. The only thing that matters is that NDP is being maximized over the reduced-form attainable possibilities set $A(\mathbf{K})$ (as if at fixed investment prices) for each instant of time.

The second condition of the maximum principle is the differential equation (7), which holds everywhere along an optimal trajectory. Unlike (6), which is a description of a perfectly competitive static economy, condition (7) is a uniquely dynamic description of a capitalstock market in competitive equilibrium. This kind of dynamic competitive equilibrium is sometimes called an "equilibrium in price expectations" or a "perfect foresight equilibrium." To understand this dynamic competitive equilibrium interpretation, we need to begin with the concept of "arbitrage." Arbitrage is the simultaneous purchase and sale of equivalent securities in order to make pure positive profits from price discrepancies. Condition (7) is essentially saying that in a perfectly competitive capital market no pure profits can be made from arbitrage. Condition (7) is a dynamic version of the basic static principle that prices in competitive equilibrium are determined where supply equals demand - because otherwise someone could make pure profits from arbitrage.

Let $\epsilon$ represent a very small period of time. Suppose that a representative agent buys one dollar's worth of capital $K_{j}$ at time $t$ at price $P_{j}^{*}(t)$. Thus, $1 / P_{j}^{*}(t)$ units of capital $K_{j}$ are purchased by the representative agent at time $t$, who then uses this extra capital to produce extra income at the flow rate (per unit of $K_{j}$ ) of $\partial \widetilde{H} / \partial K_{j}$ during the interval between time $t$ and time $t+\epsilon$, after which the agent sells the capital at time $t+\epsilon$ for a price of $P_{j}^{*}(t+\epsilon)$ dollars. At time $t+\epsilon$, the representative agent will then have made a net gain in dollars of

$$
\frac{1}{P_{j}^{*}(t)}\left(\epsilon\left[\frac{\partial \widetilde{H}}{\partial K_{j}}\right]_{* t}+P_{j}^{*}(t+\epsilon)-P_{j}^{*}(t)\right) .
$$

If the representative agent instead placed the dollar as a deposit in the national bank at 
time $t$, then the net amount gained from this bank investment at time $t+\epsilon$ would be

$r \epsilon$.

In a perfectly competitive capital market where no pure profits can be made from arbitrage, (8) must equal (9), which can be rewritten as the condition

$$
\frac{P_{j}^{*}(t+\epsilon)-P_{j}^{*}(t)}{\epsilon}=-\left[\frac{\partial \widetilde{H}}{\partial K_{j}}\right]_{* t}+r P_{j}^{*}(t) .
$$

Taking the limit as $\epsilon \rightarrow 0$, and then passing over to vector notation, equation (10) becomes exactly condition (7). If (7) did not hold, then the economy would be in disequilibrium and pure profits could be made from arbitrage by moving money from private investment in $K_{j}$ to the national bank (if (9) exceeds (8)) or from the national bank to private investment in $K_{j}$ (if (8) exceeds (9)). By transferring funds from one investment vehicle to the other, this arbitrage activity would put pressure on capital-stock prices to move in a direction closer to satisfying (7), and such price movements would not cease until no more pure profits could be made from arbitrage, meaning (7) holds fully in dynamic competitive equilibrium. ${ }^{10}$

To sum up this section, any group of economists observing a nation over time on a trajectory simultaneously satisfying (6) and (7) would swear under oath that they were witnessing a dynamic competitive equilibrium with a perfect capital market at real interest rate $r$. So if we can imagine for some economy what a dynamic competitive equilibrium with a perfect capital market at interest rate $r$ would look like, then we can simultaneously imagine the solution to the corresponding optimal control problem.

\section{Complete Accounting and Comprehensive Income}

Let the expression $Y^{*}(t)$ stand for what will be called in this paper comprehensive income (or comprehensive NDP) ${ }^{11}$ at time $t$ The formal definition of comprehensive income $Y^{*}(t)$ at time $t$ is

$$
Y^{*}(t)=\widetilde{H}\left(\mathbf{K}^{*}(t), \mathbf{P}^{*}(t)\right) .
$$

\footnotetext{
${ }^{10}$ Special cases of $(7)$ include the Hotelling Rule for non-renewable resources and the marginal product of produced capital being equal to the (real) interest rate.

${ }^{11}$ At the level of abstraction of the toy model here, there is no distinction between net domestic product and net domestic income.
} 
From (6) we could just as well write (11) along an optimal trajectory as

$$
Y^{*}(t)=C^{*}(t)+\mathbf{P}^{*}(t) \mathbf{I}^{*}(t)
$$

In the setup here, comprehensive national income is NDP as measured with the price of consumption normalized to unity and relative prices of net investment goods evaluated at the efficiency prices that correspond to a dynamic competitive equilibrium for the model. We have already mentioned that any group of economists observing a nation over time on a trajectory simultaneously satisfying (6) and (7) would swear under oath that they were witnessing a dynamic competitive equilibrium with a perfect capital market at real interest rate $r$. In this same spirit, national income statisticians at time $t$ would swear that NDP (with consumption as numeraire) is correctly measured by comprehensive national income $\left.Y^{*}(t)=C^{*}(t)+\mathbf{P}^{*}(t) \mathbf{I}^{*}(t)\right)=\widetilde{H}\left(\mathbf{K}^{*}(t), \mathbf{P}^{*}(t)\right)$.

"Complete accounting" here refers to condition (1) along with conditions (5) and (6). The significance of "complete accounting" in this toy economy is the following. As has already been explained, comprehensive national income $\left.Y^{*}(t)=C^{*}(t)+\mathbf{P}^{*}(t) \mathbf{I}^{*}(t)\right)=$ $\widetilde{H}\left(\mathbf{K}^{*}(t), \mathbf{P}^{*}(t)\right)$ along an optimal trajectory represents "perfectly complete" net domestic product (or "perfectly complete" net domestic income) with the consumption good as numeraire having a price of one. For theoretical purposes, we are thus imagining an idealized world where the coverage of capital goods is so comprehensive, and the national accounting system is so complete, that there remain no unacounted-for residual "atmospheric" growth factors. National income accounting is assumed to be "perfectly complete" because all sources of future growth have been attributed to proper investments, in the form of (1), which are fully "accounted for" by being valued at their proper competitive or efficiency prices and included in comprehensive national income as $\left.Y^{*}(t)=C^{*}(t)+\mathbf{P}^{*}(t) \mathbf{I}^{*}(t)\right)=\widetilde{H}\left(\mathbf{K}^{*}(t), \mathbf{P}^{*}(t)\right)$. Condition (1) signifies that time $t$ enters the attainable possibilities set $A(\mathbf{K}(t))$ only via the capital stocks at that time $\mathbf{K}(t)$. In this sense a "perfectly complete" production system is time autonomous.

Unfortunately, we do not now live in a world where national income accounting is complete, even though our theoretical models often assume this feature. ${ }^{12}$ Completeness is perhaps best envisioned as a limiting case, which some real-world accounting systems approach in coverage but few attain. In our actual world we cannot measure accurately all investments, many externalities are not corrected or internalized, non-convexities and distortionary taxes abound, it is often difficult to impute market-like shadow prices for nonmarket goods, imperfect competition and other non-optimal conditions exist, there are various atmospheric

\footnotetext{
${ }^{12}$ Every paper written in this area has to struggle mightily with the fact that, in practice, accounting is incomplete, and sometimes very incomplete.
} 
sources of positive or negative growth (like exogenous technological progress), which we cannot or do not include in net domestic income, and so on. (The omitted atmospheric contributions are identified primarily as a residual, which is obtained by subtracting off from actual growth the effects of all known, properly attributed, sources of growth.)

Note that, technically speaking, it is always possible to convert any time-dependent system into a time-autonomous system merely by relabeling "time" as the $(n+1)$ st capital good, whose corresponding net investment flow (or rate of change) is the positive constant +1 . And this approach would be fine for national income applications, provided we knew the efficiency price of time. Then, complete accounting for such a time-dependent system would include as the price of the $(n+1)$ st "investment" the value to the welfare-producing system of the passage of calendar time itself. The difficulty with this approach is not theoretical, but rather empirical. We are not sure where to look in a real-world economy for a decent market-based measure of the value of changes dependent on calendar time, such as the value of exogenous atmospheric technological progress or other elements of the "residual."

The primary justification usually given for studying the pure theory of complete accounting in a real world of incomplete accounting is that the pure theory can serve as a guiding beacon lighting the way toward greater completeness - by suggesting what activities to include, and how best to include them, to "green up" net domestic product or income into a more comprehensive aggregate reflecting more accurately what the future portends relative to the present. Also, the pure theory of complete accounting may be important because it will indicate how to use current income-like data to make rigorous dynamic welfare comparisons - at least in principle.

All misgivings notwithstanding, it is perhaps not unreasonable to begin an inquiry into the welfare significance of comprehensive income by postulating the perfectly complete accounting that goes along with a time-autonomous attainable possibilities set and "as if perfectly competitive" investment prices.

\section{What is Wealth (or Welfare)?}

Let $W(t)$ represent the wealth (or welfare) of the toy economy at time $t$. Wealth is a stock of welfare that capitalizes the future flow of well-being. In the model of this setup it is natural to define wealth (or welfare) as the capitalized present discounted value of all future 
consumption. ${ }^{13}$ Thus, along an optimal trajectory,

$$
W(t) \equiv \int_{t}^{\infty} e^{-r(x-t)} C^{*}(x) d x
$$

Taking the time derivative of (13) by differentiating the right-hand-side integral with respect to $t$, and simplifying the resulting expression, yields here the basic differential equation

$$
\dot{W}(t)=r W(t)-C^{*}(t)
$$

Consider the optimal control problem we have been dealing with thus far. Let $V(\boldsymbol{\Gamma})$ represent the state evaluation function, which is the maximized value of (2) (subject to constraints (1), (3), (4)) as a function of the initially given capital stocks $\boldsymbol{\Gamma}$. In words, $V(\boldsymbol{\Gamma})$ is the maximum present discounted consumption that the system can deliver, starting from the initial condition $\mathbf{K}(0)=\boldsymbol{\Gamma}$. Then, by definition, all along an optimal trajectory it must hold that

$$
W(t)=V\left(\mathbf{K}^{*}(t)\right)
$$

Furthermore, it can be shown ${ }^{14}$ that, all along an optimal trajectory, the relationship

$$
V^{\prime}\left(\mathbf{K}^{*}(t)\right)=\mathbf{P}^{*}(t)
$$

must hold, where $V^{\prime}(\mathbf{K})=\left\{\partial V / \partial K_{j}\right\}$. Condition (16) means that at all times $t$ along the optimal trajectory the efficiency price $P_{j}^{*}(t)$ of the investment good $j$, which appears in the maximized Hamiltonian (6), is the partial derivative of the state evaluation function with respect to capital $K_{j}$ evaluated at $\mathbf{K}=\mathbf{K}^{*}(t)$.

Now take the time derivative of both sides of equation (15), yielding by the chain rule of differentiation

$$
\dot{W}(t)=V^{\prime}\left(\mathbf{K}^{*}(t)\right) \dot{\mathbf{K}}^{*}(t)=\mathbf{P}^{*}(t) \mathbf{I}^{*}(t)
$$

where the last equality is from (16) and (3).

Next, combine (14) with (17), which yields, after rearrangement, the fundamental relationship between wealth and income:

$$
r W(t)=C^{*}(t)+\mathbf{P}^{*}(t) \mathbf{I}^{*}(t)=Y^{*}(t) .
$$

\footnotetext{
${ }^{13}$ The literature often misidentifies inclusive wealth (at time $t$ ) as the value of contemporaneous capital stock $\mathbf{P}^{*}(t) \mathbf{K}^{*}(t)$. This is a mistake because $\mathbf{P}^{*}(t) \mathbf{K}^{*}(t)$ does not have welfare significance, even in the simplest cases.

${ }^{14}$ See Weitzman (2003). I am assuming here for simplicity that the function $V(\boldsymbol{\Gamma})$ is differentiable. A more general case is treated in Weitzman (2003).
} 


\section{6 "Sustainability" as "Sustainable-Equivalent Consump- tion"}

Recent times have witnessed a greatly heightened awareness of the interactions between economic, social, and environmental issues. People throughout the world have become much more sensitive to the important possible links between their own human societies and the natural environmental surroundings within which these societies may thrive or fail. Terms like "green accounting" and "sustainability" have found their way into the popular lexicon. What do we mean by these terms?

The first term is relatively easy to explain. "Green accounting" in the formulation of this paper is more or less synonymous with what we have called "complete accounting" because all sources of future growth (including, as negative investments, resource depletion, degradation of natural capital, and so forth) have been attributed as proper net investments, which are fully "accounted for" by being valued at their proper efficiency prices and included in national income.

But what is to be understood by the fuzzier concept of "sustainability"? The Bruntland Commission on Environment and Development (1987) famously described "sustainable development" as being "development that meets the needs of the present without compromising the ability of future generations to meet their own needs." ${ }^{15}$ Unfortunately, this definition is still much too vague to be operationally useful. The purpose of this section is not to demolish the concept of "sustainability," which has, I believe, a legitimate core essence in the form of "sustainability equivalence," but rather to eliminate the fuzziness by formalizing and making more operational the basic economic ideas underlying this concept of "sustainability equivalence." At the end of the day it will turn out that there is a fundamental connection between "comprehensive income" (with complete accounting) and "sustainable-equivalent consumption."

The word "sustainability" is often used but rarely defined carefully. It can have a great many meanings, and even nuances, which may vary greatly depending on the user and the context of the usage. ${ }^{16}$ This leaves a lot of room for an author to pick, choose, and use his/her favorite definition, within reason.

At the broadest level, sustainability refers in some way to the ability to "sustain" in the sense of keeping constant something across time. That is, the word sustainability connotes a constancy-like property of "something."

The various notions of sustainability then seem to differ primarily in the "something"

\footnotetext{
${ }^{15}$ World Comm. Environ. Dev. (1987), page 43.

${ }^{16}$ See Pezzey (1992) for a survey of some of the many various meanings of "sustainability."
} 
that is supposed to be sustained - usually in the degree of specificity of the "something" to be sustained. For example, "sustainability" in the narrow sense might refer to maintaining at constant levels something quite particular - forests, or wetlands, or landscapes, or mineral reserves, or fisheries - so that future generations might enjoy the same usage of these specific forms of natural-resource capital as we do now. Although "sustainability" in this narrow sense might sometimes be a practical shorthand way of expressing certain desirable conservation goals, it seems too arbitrary to serve as a general principle for guiding economic development. As a practical matter, we simply cannot have economic growth, with its attendant goal of raising people out of poverty, while preserving everything that has any conceivable natural or aesthetic value. Taken to an extreme, the injunction to pursue "sustainable development" in the narrowly specific sense of leaving intact particular forms of natural capital would paralyze development, since no growth is possible without causing levels of something to decline somewhere.

Sector-specific or use-specific or micro-specific definitions of "sustainability" are highly problematic in several ways. It is left up in the air what is the particular set of specific resources to be sustained, and who selects the list. In technical terms, the principle of sustainable development at this level of specificity is not invariant to aggregation and is highly sensitive to which sector's output is chosen to be sustained. For example, what is sustainable for one species of plant or animal may be unsustainable for other species of plant or animal.

Does all of this mean that the concept of sustainability is useless? I don't think so. In its appropriate form, the idea of sustainability is so extremely appealing as an intuitive conceptual device for thinking seriously about the environmental big-picture side of economic development that it is difficult to imagine how we might do without it. The approach taken here is to adopt what I think is a particularly fruitful definition (out of the many possible definitions) as follows. What we will understand here by the word "sustainability" - as applied to a particular development program - is the sustainable-equivalent consumption that the program generates. In other words, the sustainability of a development program is to be identified with the hypothetical constant level of consumption that would yield the same wealth or welfare as the actual dynamic trajectory.

More formally, we define sustainable-equivalent consumption (at time $t$ ) to be the hypothetical quasi-fixed forward-looking consumption level $\bar{C}_{S}(t)$ that satisfies the equation

$$
\int_{t}^{\infty} e^{-r(x-t)} \bar{C}_{S}(t) d x=\int_{t}^{\infty} e^{-r(x-t)} C^{*}(x) d x .
$$

"Sustainable-equivalent consumption" $\bar{C}_{S}(t)$ signals to us (at time $t$ ) what future con- 
sumption portends (on average) relative to current consumption $C^{*}(t)$. If $\bar{C}_{S}(t)>C^{*}(t)$ then future consumption looks "better" (on average) than present consumption, or, loosely speaking, the welfare level expressed by present consumption can be (more than) "sustained" into the future. Conversely, if $\bar{C}_{S}(t)<C^{*}(t)$ then future consumption looks "worse" (on average) than present consumption because the welfare level expressed by present consumption cannot be "sustained" into the future.

Later it will be shown that

$$
\bar{C}_{S}(t)-C^{*}(t)=\mathbf{P}^{*}(t) \mathbf{I}^{*}(t)
$$

Equation (20) indicates that the difference between sustainable-equivalent consumption $\bar{C}_{S}(t)$ and current consumption $C^{*}(t)$ is exactly captured quantitatively by current net investment $\mathbf{P}^{*}(t) \mathbf{I}^{*}(t)$. If $\bar{C}_{S}(t)=C^{*}(t)$, then $\mathbf{P}^{*}(t) \mathbf{I}^{*}(t)=0$, meaning that positive accumulation investments in produced means of production just exactly offset negative depletion investments; in this razor's-edge case, future consumption looks the same (on average) as current consumption. ${ }^{17}$

\section{What is Income?}

Speaking generally, the proper definition of "income" is one of the most elusive subjects in economics. It is also one of the most important, as witnessed by the great interest in income accounting at all levels throughout the economy, including national income accounting. Whatever difficulties there may be in measuring income, such measures are attempted very frequently in practice. Three great economists are associated with three different basic approaches to defining income. In what follows, income at time $t$ will be symbolized by the notation $Y(t)$.

For Irving Fisher, wealth was the primary concept and income was then defined as an interest-like return on wealth. ${ }^{18}$ In the notation of this paper, Fisherian income $Y_{F}(t)$ is defined as

$$
Y_{F}(t) \equiv r W(t)
$$

Erik Lindahl (1934) argued that the income of a period should be identified with the sum of consumption plus the net increase of wealth over the period. In the notation of this

\footnotetext{
${ }^{17}$ A variant of this situation is sometimes called "Hartwick's rule," after Hartwick (1977). On this subject, see also Asheim, Bucholz, and Withagen (2003).

${ }^{18}$ This is my paraphrasing of Fisher's basic position. See for example Fisher (1906).
} 
paper, "Lindahlian income" (at time $t$ ) $Y_{L}(t)$ is defined as

$$
Y_{L}(t) \equiv C^{*}(t)+\dot{W}(t)
$$

I think that it is fair to say that contemporary national income accounting is centered conceptually on what is frequently identified as the "Hicksian" concept of income. In John Hicks's own words, income is "the maximum amount which can be spent during a period if there is to be an expectation of maintaining intact the capital value of prospective returns."19 Hicks was well aware that all concepts of income are at best a "rough approximation" with "far too much equivocation in their meaning" - as opposed to constituting a "strict logical category." He characterized examples of his own approach as "an approximation to the central meaning of the income concept," to be contrasted with "an analysis which aims at logical precision."

All of this notwithstanding, Hicks was firm in his own mind about his "central meaning" when he wrote "the calculation of income consists in finding some sort of standard stream of values whose present capitalized value equals the present value of the stream of receipts which is actually in prospect. It is a standard stream in that it maintains some sort of constancy, as against the actual expected stream of receipts, which may fluctuate in any manner whatsoever ... We ask, not how much a person actually does receive in the current week, but how much he would be receiving if he were getting a standard stream of the same present value as his actual expected receipts. That amount is his income." 20

In a perceptive essay entitled "The Concept of Income in Economic Theory," Nicholas Kaldor has characterized Hicks's approach to defining income as follows. "The novelty of this [Hicks] approach to the income concept is that it eschews any connection between the notion of income and the notion of capital. Fisher, Lindahl, and the other writers on the subject invariably looked upon income as the yield derived from some given source: in the case of Fisher, it is the net yield of capital goods after elimination of all 'double counting'; for the others, it is the net yield after deducting (or adding as the case may be) whatever is necessary to maintain the 'source' or the 'corpus' intact. In Hicks's approach the source or corpus from which the income is derived disappears altogether as a separate entity capital appears only as the capitalized value of a certain future prospect and income as the 'standard stream equivalent' of that prospect. Capital and income are thus two different ways of expressing the same thing, not two different things." 21

In the notation of this paper, Hicksian standard-stream-equivalent income (at time $t$ )

\footnotetext{
${ }^{19}$ All quotations attributed here to Hicks are taken from Hicks (1946), chapter 14.

${ }^{20}$ Hicks (1946), page 184, emphasis (italics) in the original.

${ }^{21}$ Kaldor (1955) chap. 5, sec. 4 (income as "standard stream"), italics (emphasis) in original.
} 
$Y_{H}(t)$ is defined as the forward-looking solution of the equation

$$
\int_{t}^{\infty} e^{-r(x-t)} Y_{H}(t) d x=\int_{t}^{\infty} e^{-r(x-t)} C^{*}(x) d x .
$$

There is obviously a close connection between Hicksian standard-stream income $Y_{H}$ defined by (23) and sustainable-equivalent consumption $\bar{C}_{S}$ defined by (19). In fact, the two are equal because they both satisfy the same equation.

\section{Connecting the Concepts}

In the model of this paper, a number of very strong assumptions have been made. But then a very strong equivalence connection can be established among the various concepts of the paper. Under perfectly-complete accounting, comprehensive income $Y^{*}(t)$ equals sustainable-equivalent consumption $\bar{C}_{S}(t)$ equals Fisherian income $Y_{F}(t)$ equals Lindahlian income $Y_{L}(t)$ equals Hicksian income $Y_{H}(t)$. In symbols,

$$
Y^{*}(t)=\bar{C}_{S}(t)=Y_{F}(t)=Y_{L}(t)=Y_{H}(t) .
$$

The proof of proposition (24) comes from the following set of equivalences.

Sustainable-equivalent consumption equals Hicksian income equals Fisherian income because (from comparing (19), (23) and making use of (13), (21))

$$
\bar{C}_{S}(t)=Y_{H}(t)=\frac{\int_{t}^{\infty} e^{-r(x-t)} C^{*}(x) d x}{\int_{t}^{\infty} e^{-r(x-t)} d x}=r \int_{t}^{\infty} e^{-r(x-t)} C^{*}(x) d x=r W(t)=Y_{F}(t) .
$$

Lindahlian income equals Fisherian income equals comprehensive income because (from combining together (22), (14), (21), (18), and (12))

$$
Y_{L}(t)=C^{*}(t)+\dot{W}(t)=r W(t)=Y_{F}(t)=C^{*}(t)+\mathbf{P}^{*}(t) \mathbf{I}^{*}(t)=Y^{*}(t) .
$$

The central result (24) indicates a strong sense of how future welfare may be compressed into present income, however present income is defined (within reason).

\section{Concluding Remarks on Wealth and Income}

The toy model of this paper is starkly oversimplified. It is being presented at an extremely high level of abstraction. Many strong assumptions have been made to obtain the strong 
equivalences of (24). Readers can make up their own minds, but I think that this toy model is useful as a conceptual framework for thinking rigorously about wealth and income (and sustainability and accounting). The concepts explored here are deceptively tricky and it is hard for me to see how else they might be crisply exposited and rigorously analyzed.

The overarching theme of this paper is the tight relationship between comprehensive wealth and comprehensive income. To paraphrase Kaldor, ${ }^{22}$ in the toy model being presented here properly-accounted wealth and properly-accounted income are (at least in principle and at a high level of abstraction) two different ways of expressing the same thing, not two different things. Several consequences emerge from the basic duality between wealth (or welfare) and income. In this conclusion I mention only what I consider to be perhaps the single most important prototype application.

Question: how can money income be used to make welfare comparisons of the same economy over time (or different economies across space)? Answer (at the high level of simplification and abstraction of this paper, with both economies having the same constant rate of return on consumption): one situation gives higher present discounted consumption than the other if and only if current comprehensive income (with the single consumption good as the common real numeraire) is higher in the one situation than in the other.

The above answer to the most basic question about the relation between current money income and future welfare is so simple that its power can easily be overlooked. Imagine any two dynamic economies. The two economies might be arbitrarily different. They may have completely different endowments or completely different production opportunities. For example, one economy may have mineral reserves, but cannot use machines to grow. Another economy may be able to use accumulated machines to grow but lacks mineral resources. And so forth. The only thing in common between the two economies is that they are both behaving as if they are maximizing present discounted consumption at the same discount rate. The two economies may be grinding out completely different growth trajectories.

Suppose we want to compare dynamic welfare between the two economies. We want to know what is the difference between the two in present discounted consumption. Suppose further that the only thing we can observe about the two economies is their current real comprehensive income with the single consumption good as numeraire. (This is equivalent here to observing money income in both economies and being able to convert the money income of one economy into the monetary units of the other by using as a price deflator socalled "purchasing power parity," which here is just the ratio of the two consumption-good money prices.) The observing economist knows nothing else about these two economies

\footnotetext{
${ }^{22}$ Kaldor (1955) chap. 5, sec. 4 (income as "standard stream").
} 
except their real national income.

Then the striking result is that the numerical difference in present discounted consumption between the above two economies is exactly the numerical difference in real comprehensive income divided by the consumption discount rate. With complete accounting in this situation, all relevant information for making dynamic future welfare comparisons is contained in current comprehensive income. Such a result is remarkable because it means that changes in forward-looking welfare can (at least in principle and under strong assumptions) be picked up exactly by changes in the flow of comprehensive current income. Frankly, what I think is remarkable here is not so much that strong abstractions are required to obtain the strong equivalences of (24), but that such strong equivalences as (24) exist at all under recognizable abstractions. In this highly-idealized situation, current comprehensive income is a sufficient statistic for any dynamic welfare comparisons. To state this proposition rigorously, and to explore its numerous ramifications, is, I think, the main contribution of the present paper.

\section{References}

[1] Asheim, Geir, Wolfgang Bucholz, and Cees Withagen (2003). "The Hartwick Rule: Myths and Facts." Environmental and Resource Economics, 25, 129-150.

[2] Feldstein, Martin (1997). "The Costs and Benefits of Going from low inflation to Price Stability." In C.D. Romer and D.H. Romer, eds, Reducing Inflation: Motivation and Strategy. Chicago: University of Chicago Press.

[3] Fisher, Irving (1906). The Nature of Capital and Income. New York: Macmillan.

[4] Hamilton, Kirk, and John Hartwick (2014). "Wealth and Sustainability." Oxford Review of Economic Policy, 30 (1), 170-187.

[5] Hicks, John R. (1946). Value and Capital. 2nd ed. Oxford: Oxford University Press.

[6] Hartwick, John M. (1977). "Intergenerational Equity and the Investment of Rents from Exhaustible Resources." American Economic Review, 65, 972-4.

[7] Jorgenson, Dale W. (1994). "Investment and Economic Growth." The Simon Kuznets Lectures, Yale University.

[8] Kaldor, Nicholas (1955). An Expenditure Tax. London: Allen and Unwin. 
[9] Lindahl, Erik (1934). "The Concept of Income." In G. Bagge, ed., Economic Essays in Honor of Gustaf Cassel. London: George Allen \& Unwin.

[10] Nordhaus, William D. (1994). Managing the Global Commons: The Economics of Climate Change. Cambridge MA: MIT Press.

[11] Pezzey, John (1992). "Sustainable Development Concepts: An Economic Analysis." World Bank Environment Paper no. 2. Washington, D.C.: World Bank.

[12] Solow, Robert M. (1963). Capital Theory and the Rate of Return. Amsterdam: NorthHolland Publishing Company.

[13] Solow, Robert M. (1970). Growth Theory: An Exposition. New York: Oxford University Press.

[14] Weitzman, Martin L. (1970). "Aggregation and Disaggregation in the Pure Theory of Capital and Growth: A New Parable." Cowles Foundation Discussion Paper no. 292, Yale University. Accessible at cowles.yale.edu/cfdp.

[15] Weitzman, Martin L. (1976). "On the Welfare Significance of National Product in a Dynamic Economy." Quarterly Journal of Economics 90: 156-162.

[16] Weitzman, Martin L. (2003). Income, Wealth, and the Maximum Principle. Cambridge MA: Harvard University Press.

[17] World Commission on Environment and Development (1987). Our Common Future ("The Bruntland Report"). New York: Oxford University Press. 